\title{
Poemas de Carlos Ernesto García y Marta Leonor González
}

\section{Carlos Ernesto García}

Nacido en 1961, este poeta salvadoreño radica en Barcelona desde hace varios años. Acaba de publicar un libro de viajes: El sueño del dragón, que se suma a sus poemarios Hasta la cólera se pudre y A quemarropa el amor. Su obra ha sido traducida a varios idiomas.

SE ME CAYÓ LA CASA

Lo que me contó un campesino de San Agustín, donde los terremotos del 2001 en El Salvador, destruyeron miles de viviendas.

Primero fue la sacudida y el rugido de la tierra

Era como si debajo de mis pies corrieran al galope los demonios subidos sobre grandes serpientes

Después fue el griterío la ladradera de perros

hasta imponerse el silencio.

Corría cuesta abajo

entre una nube de polvo

$y$ un abanico de desgracias 
La farmacia

la escuela

el mercado

la iglesia

estaban en el suelo

La casa del sastre

la del peluquero

la del dentista

la del panadero

la de mi comadre Lupe

eran una explanada de tierra

y una tormenta de lamentos

No había adonde preguntar

pues las gentes andaban locas

gritando nombres

A lo lejos

una bandera ondeaba

sobre el único edificio en pie:

el de la comandancia del pueblo.

\section{El hermano LejaNo}

Lo encontré en Nueva Orleáns sirviendo en un restaurante de comida mexicana

Al principio dudé

pero no

si era chaparrito

moreno y de bigote lampiño

labios gruesos

pelo de un negro azabache

y ojos rasgadamente indígenas.

Pero él

también me reconoció de inmediato 
como a uno de los suyos

pues no somos tan distintos

Pero yo diría que más bien

me descubrió in fraganti

por esa manera de tomar que tengo

cuando viajo fuera de casa

y los recuerdos de la infancia

golpean las puertas del alma.

Nos citamos en el bar Napoleón que quedaba a la vuelta

Un famoso bebedero de la ciudad que después me encontré en una película de Kevin Kosner

"Antes de estos cuatro empleos que tengo yo era ordenanza -me dijoen un centro de gobierno

Ahí todos hablaban de algún familiar en los Estados Unidos

Ahora algunas noches

cuando me meto en la cama

abrazo a mi mujer y lloramos amargamente hasta quedarnos dormidos como dos niños soñando a veces con nuestros hijos

que se quedaron a la espera

de viajar a esta tierra prometida

donde vive y muere el hermano lejano". 
Los mismos

que sacudieron a patadas la palabra que golpearon por las noches

la puerta de los versos

que enterraron

el cuerpo del poeta

en un lugar desconocido

y leyeron proclamas militares

Los mismos

que pagaron al verdugo

que negaron el pan al hambriento

que escupieron en las manos del prisionero

cuando este les pidió un vaso de agua

para calmar la sed de sus hermanos

Los mismos

que se limpiaron en el retrete

con los versos de Alfonso Hernández

de "Chema" Cuellar

de Jaime Suárez y de Roque Dalton

y luego se pusieron a reír a carcajadas

en medio de la tristeza de los hombres

Queridos poetas

venidos de lejos con sus versos

No se dejen engañar

no se dejen dar espejitos

a cambio de sus versos

porque aún

está fresquita la sangre

de los muchachos poetas

que no se ven 
y están en todas partes gritando iiiiPRESENTE!!!!!

\section{Marta LeOnor GonzÁlez}

Nacida en Nicaragua, en 1972, Marta Leonor González destaca, junto a su importante trabajo literario, como editora y promotora cultural. Huérfana embravecida es el título de su primer poemario publicado. Dirige el suplemento La Prensa Literaria, así como la revista cultural 400 elefantes.

No ESTÁ

Qué de mí

si en mi cama se extiende

enrollada en mi cuello

absorta de delirios

con sus esmeraldas me mira.

No es el ungido escorpión

en el lecho entre horas,

no está. Se retuerce

me ataca con el flagelo

de su cola.

Escamosa va

repta, serpentea

fluctúa en serpentín

$y$ en retroceso arremete

en azotaína con artilugios y añagaza.

\section{DieZ AÑos DESPUÉS}

El corazón que está en mis manos dice: lentitud de vida corre por la sangre, los restos de esta tarde ser irán conmigo, mi mañana la guardarás entre tus ojos como dos lágrimas puras de invierno, 
las venas se enfriarán como vigas de cemento opacas de naturaleza.

Y recogerás ese corazón que una vez dijo: hija, madre, niño, taxi, avión, caballo, rosas negras y blancas en un jardín que nunca recordarás.

Y como días en tu bolso lleno de alfileres se guardarán la risa, las manos, tu silencio. $\mathrm{Y}$ aquella barba que afeitabas muy bien los días de tu cumpleaños.

\section{Si VES UN GATO NEGRO, DECíA MI ABUELA}

Manadas de gastos merodean la noche de mis tejados, manosean el secreto de los amantes, y con sus garras afiladas corcovean sobre la hembra

lloran porque están solos, [herida, recorren las calles abandonadas, con el temor que una mano los condene, olfatean un olor a pollo asado, a pan recién horneado y en el solar, macho y hembra, aislados, perteneciéndose en cada marejada. Si ves un gato negro, decía mi abuela, te abrumará de noches, y con las uñas te sacará los ojos.

Como auténticos cuervos de la existencia, arrimados a la puerta con aire de perdón, no sabrán que esa misma noche, serán gatos en la ventanilla de un bus azul. 